A method to i ncrease sheet el ect ron densi ty and mobi I ity by vacuum anneal ing for $\mathrm{Ti} / \mathrm{Al}$ deposi ted Al GaN/GaN het er ost r uct ur es

\begin{tabular}{|l|l|}
\hline 著者 & $\begin{array}{l}\text { Tokuda H rokuni , Koj i ma Toshi kazu, Kuzuhar a } \\
\text { Nasaaki }\end{array}$ \\
\hline $\begin{array}{l}\text { j our nal or } \\
\text { publ i cat i on t i t l e }\end{array}$ & Appl i ed Physi cs Let ter s \\
\hline vol une & 101 \\
\hline page range & 82111 \\
\hline year & $2012-08$ \\
\hline URL & ht t p: //hdl . handl e. net /10098/7418 \\
\hline
\end{tabular}




\section{AIP Applied Physics \\ Letters}

\section{A method to increase sheet electron density and mobility by vacuum annealing for Ti/Al deposited AlGaN/GaN heterostructures}

Hirokuni Tokuda, Toshikazu Kojima, and Masaaki Kuzuhara

Citation: Appl. Phys. Lett. 101, 082111 (2012); doi: 10.1063/1.4748169

View online: http://dx.doi.org/10.1063/1.4748169

View Table of Contents: http://apl.aip.org/resource/1/APPLAB/v101/i8

Published by the American Institute of Physics.

\section{Related Articles}

Optomechanical photoabsorption spectroscopy of exciton states in $\mathrm{GaAs}$

Appl. Phys. Lett. 101, 082107 (2012)

Importance of the correct Fermi energy on the calculation of defect formation energies in semiconductors Appl. Phys. Lett. 101, 082105 (2012)

A transient electron transport analysis of bulk wurtzite zinc oxide

J. Appl. Phys. 112, 033720 (2012)

The CulnSe2-Culn3Se5 defect compound interface: Electronic structure and band alignment Appl. Phys. Lett. 101, 062108 (2012)

Reconstructions and electronic structure of (112) and (11) semipolar AIN surfaces

J. Appl. Phys. 112, 033510 (2012)

\section{Additional information on Appl. Phys. Lett.}

Journal Homepage: http://apl.aip.org/

Journal Information: http://apl.aip.org/about/about_the_journal

Top downloads: http://apl.aip.org/features/most_downloaded

Information for Authors: http://apl.aip.org/authors

\section{ADVERTISEMENT}

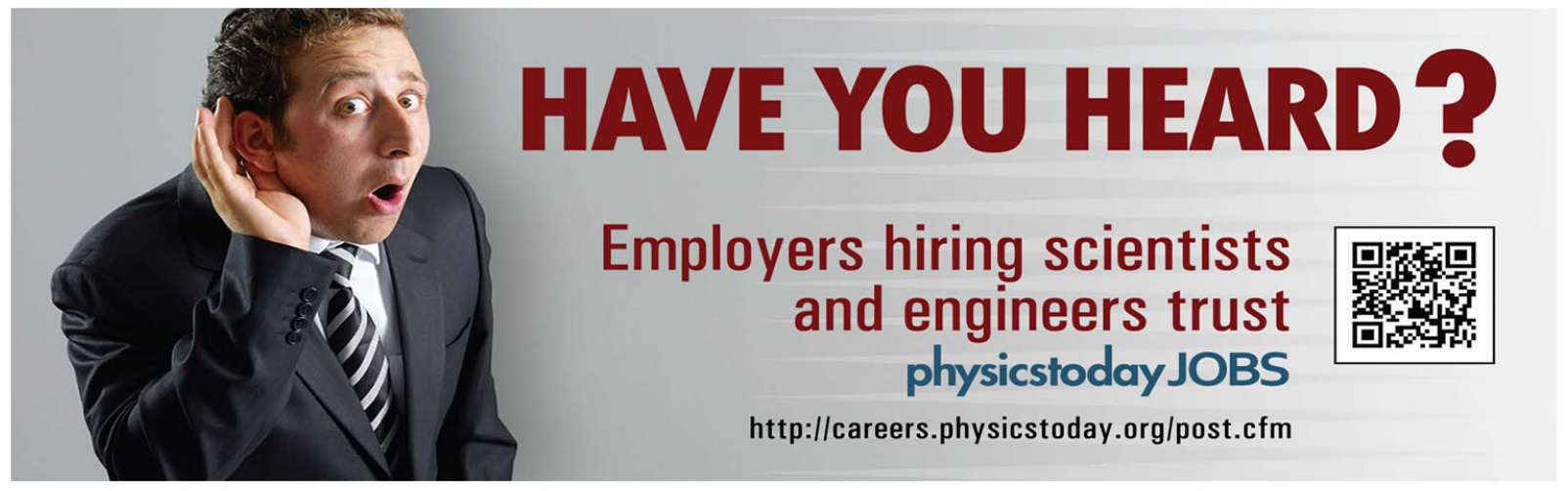




\title{
A method to increase sheet electron density and mobility by vacuum annealing for Ti/Al deposited AIGaN/GaN heterostructures
}

\author{
Hirokuni Tokuda, Toshikazu Kojima, and Masaaki Kuzuhara \\ Graduate School of Engineering, University of Fukui, 3-9-1 Bunkyo, Fukui 910-8507, Japan
}

(Received 4 June 2012; accepted 13 August 2012; published online 24 August 2012)

\begin{abstract}
Temperature dependence of sheet electron density $\left(n_{\mathrm{s}}\right)$ and mobility $(\mu)$ for Ti/Al deposited $\mathrm{AlGaN} / \mathrm{GaN}$ heterostructures annealed in vacuum has been investigated using Hall effect measurements. The vacuum annealing at $1020 \mathrm{~K}$ caused the increase in both $n_{\mathrm{s}}$ and $\mu$ at room temperature, with the amount of one order of magnitude and $65 \%$, respectively, as compared to without annealed sample. The amount of increase was much less for only Ti or Al deposited or totally thin Ti/Al deposited sample. The origin of the increase is attributed to tensile strain induced by vacuum annealing. The method is useful for reducing the ohmic contact resistivity and/or the access resistance between source and gate in AlGaN/GaN HEMTs. (C) 2012 American Institute of Physics. [http://dx.doi.org/10.1063/1.4748169]
\end{abstract}

AlGaN/GaN high electron mobility transistors (HEMTs) are attractive device for high output power and high temperature operations. This is enabled by high sheet electron density induced at $\mathrm{AlGaN} / \mathrm{GaN}$ interface and GaN's high breakdown electric field. In order to extract high performance from HEMTs, sheet electron density $\left(n_{\mathrm{s}}\right)$ and mobility $(\mu)$ are key parameters. Higher $n_{\mathrm{s}}$ and $\mu$ are desirable for obtaining better performance. However, $n_{\mathrm{s}}$ is mainly determined by structural parameters of $\mathrm{AlGaN}$ layer, that is, $\mathrm{Al}$ composition, thickness, and surface barrier height $\left(\Phi_{\mathrm{B}}\right)^{1,2}$ Although $n_{\mathrm{s}}$ is increased by making $\mathrm{Al}$ composition high and/or AlGaN layer thick, $\mu$ tends to decrease due to the strong alloy and interface roughness scatterings. ${ }^{3-6}$

Another way to increase $n_{\mathrm{s}}$ is to introduce strain in AlGaN barrier layer by depositing, for example, SiN layer on AlGaN surface. ${ }^{7-10}$ Azize and Palacios showed that $n_{\mathrm{s}}$ and $\mu$ were increased by controlling the biaxial strain with etching $\mathrm{Si}$ substrate from the backside. ${ }^{11}$ However, the amount of increase so far is limited to $20 \%-30 \%$ and higher increase is preferable.

In this letter, a method to increase both $n_{\mathrm{s}}$ and $\mu$ (hereafter referred to as $n_{\mathrm{s}} / \mu$ ) is described. The method is based on annealing $\mathrm{AlGaN} / \mathrm{GaN}$ heterostructures deposited by $\mathrm{Ti} / \mathrm{Al}$ in vacuum. The increase of $n_{\mathrm{s}} / \mu$ was confirmed by temperature dependent Hall effect measurements (van der Pauw technique) at temperatures from $300 \mathrm{~K}$ to $1020 \mathrm{~K}$. One order of magnitude higher in $n_{\mathrm{s}}$ and $65 \%$ higher in $\mu$ were observed.

Epitaxial layers used in this study were grown by metal organic chemical vapor deposition (MOCVD) on a c-plane three inch sapphire substrate. After the growth of nucleation buffer layer, undoped $\mathrm{GaN}$ channel and undoped $\mathrm{Al}_{0.25} \mathrm{Ga}_{0.75} \mathrm{~N}$ barrier layers with thickness of $3 \mu \mathrm{m}$ and $25 \mathrm{~nm}$, respectively, were successively grown. Before starting the device process, surface was cleaned by organic solvents (acetone and ethanol), buffered HF, and rinsed by de-ionized water. Device processing was initiated by reactive ion etching (RIE) for remaining the active region with $100 \mathrm{~nm}$ depth isolation mesa using $\mathrm{Cl}_{2}$ and $\mathrm{BCl}_{3}$ gases. Ohmic metals consisting of Ti/Al/Mo/Au $(15 / 60 / 35 / 50 \mathrm{~nm})$ were evaporated in the four corners to obtain van der Pauw configuration. The wafer was alloyed at $850^{\circ} \mathrm{C}$ for $30 \mathrm{~s}$ in $\mathrm{N}_{2}$ flow to ensure good ohmic contacts. Ti/Au (10/100 nm) evaporation was followed for pad metal. After ohmic contact formation, Ti/Al was evaporated in the center of sample with varying $\mathrm{Ti}$ and $\mathrm{Al}$ thickness. Only $\mathrm{Ti}$ or $\mathrm{Al}$ evaporated sample was also prepared for comparison. Cross sectional and top views of the fabricated sample are shown in Figs. 1(a) and 1(b), respectively. The sample size was $7 \times 7 \mathrm{~mm}^{2}$ and the diameter of center circle was $5 \mathrm{~mm}$.

The processed sample was set to Hall measurement system (Toyo technica ResiTest 8310) and $n_{\mathrm{s}} / \mu$ were measured with increasing and decreasing temperatures ranging from $300 \mathrm{~K}$ (room temperature) to $1020 \mathrm{~K}$. The measurements were carried out in vacuum (around $1 \times 10^{-3}$ Torr) with the applied magnetic field of 0.55 Tesla. The $\mathrm{f}$ values were $0.95-1.0$ for all the measurements indicating that the fabricated samples were isotropic and uniform.

Figures 2(a) and 2(b) show temperature dependences of $n_{\mathrm{s}}$ and $\mu$, respectively, for Ti/Al thickness of $100 / 100 \mathrm{~nm}$. In the figures, open and closed circles correspond to the results for increasing and decreasing temperatures, respectively. The initial values of $n_{\mathrm{s}}$ and $\mu$ measured at $300 \mathrm{~K}$ were $0.98 \times 10^{13} \mathrm{~cm}^{-2}$ and $1330 \mathrm{~cm}^{2} / \mathrm{Vs}$, respectively. With increasing temperature, $n_{\mathrm{s}}$ showed sudden increase at $520 \mathrm{~K}$ and had a peak of $2.8 \times 10^{14} \mathrm{~cm}^{-2}$ at $820 \mathrm{~K}$. As the temperature decreased from $1020 \mathrm{~K}, n_{\mathrm{s}}$ was slightly increased, showed a peak at $620 \mathrm{~K}$, and then monotonously decreased to $1.1 \times 10^{14} \mathrm{~cm}^{-2}$ at room temperature. Surprisingly, $n_{\mathrm{s}}$ at $300 \mathrm{~K}$ was eleven times higher than the initial one. Furthermore, $\mu$ was also increased as shown in Fig. 2(b). It showed a hump at $520 \mathrm{~K}$ with the increase of temperature, which probably corresponded to the sudden increase observed in $n_{\mathrm{s}}$, and monotonously decreased. With the temperature decrease from $1020 \mathrm{~K}, \mu$ was increased monotonously without showing the hump. After vacuum annealing, $\mu$ at room temperature was $2190 \mathrm{~cm}^{2} / \mathrm{Vs}$, which was $65 \%$ higher than the initial value. Similar measurements were performed for samples having different Ti/Al thickness. The results are summarized in Table I. All the samples showed similar temperature dependences as shown in Fig. 2, that is, sudden 


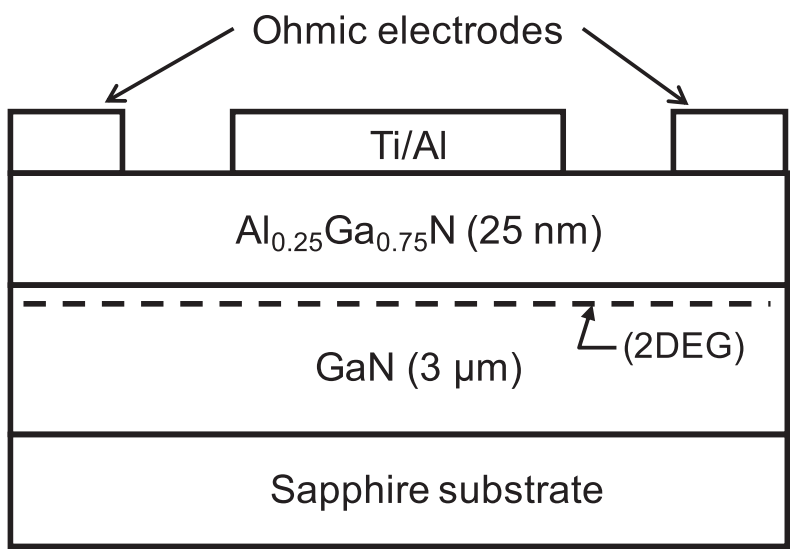

(a)

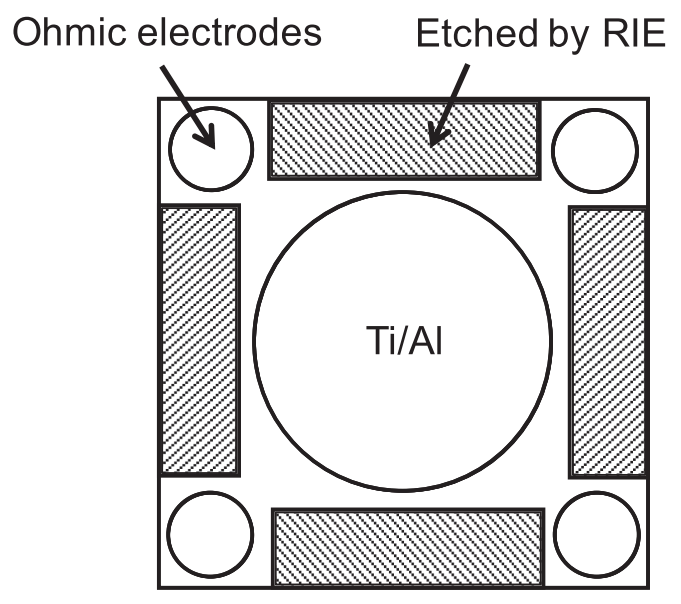

(b)

FIG. 1. Cross sectional (a) and top view (b) of the fabricated sample. The hatching is the mesa etched region. The sample size is $7 \times 7 \mathrm{~mm}^{2}$ and the diameter of center circle is $5 \mathrm{~mm}$.

increase of $n_{\mathrm{s}}$ at around $520 \mathrm{~K}$, having a peak with increasing temperature, and monotonous decrease with decreasing temperature. However, the ratio of initial $n_{\mathrm{s}}$ to vacuum annealed (VA) one, $n_{\mathrm{s} 2} / n_{\mathrm{s} 1}$, and that of initial $\mu$ to VA one, $\mu_{2} / \mu_{1}$, showed marked differences with $\mathrm{Ti} / \mathrm{Al}$ thickness. It was found that: (i) the increase of $n_{\mathrm{s}}$ was not observed or much less and $\mu$ was decreased for only $\mathrm{Ti}$ or Al deposited sample

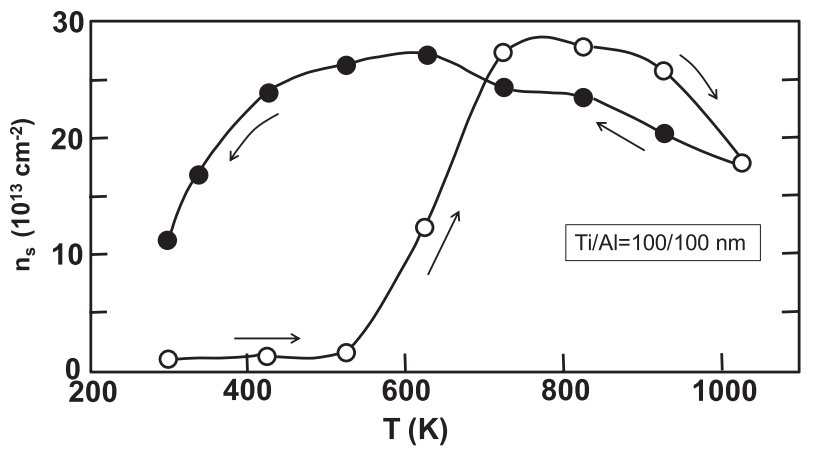

(a)

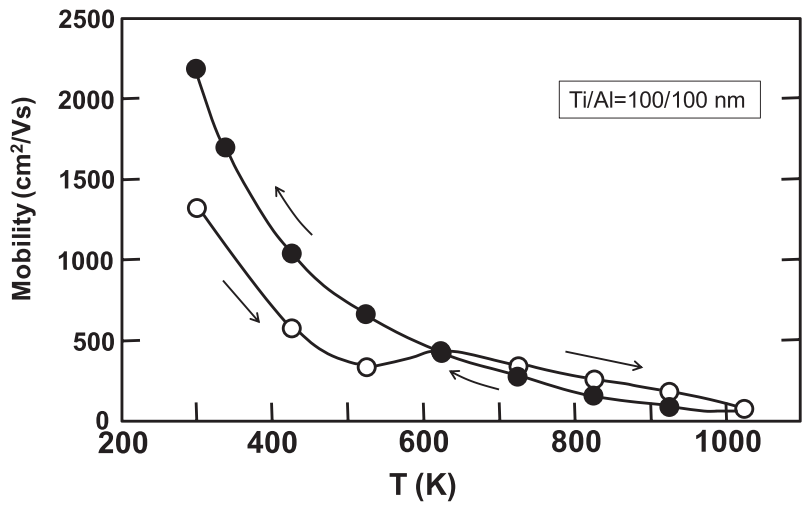

(b)

FIG. 2. Temperature dependence of sheet electron density (a) and mobility (b) for Ti/Al thickness of $100 / 100 \mathrm{~nm}$. Open and closed circles correspond to increasing and decreasing temperatures, respectively. The arrows show the temperature increase/decrease directions.

(rows 1, 2, and 7 in Table I), (ii) the amount of $n_{\mathrm{s}}$ increase was small when the total Ti/Al thickness was thin $(30 \mathrm{~nm})$ (row 3 in Table I), and (iii) the amount of $n_{\mathrm{s}} / \mu$ increase was independent of $\mathrm{Ti} / \mathrm{Al}$ thickness in case of total thickness over $65 \mathrm{~nm}$ (rows 4-6 and 8-9 in Table I). The measured samples were kept for one week in the air, and $n_{\mathrm{s}} / \mu$ were measured again at room temperature. The results were almost the same as after vacuum annealed ones within the experimental error of $\pm 3 \%$, which indicated that $n_{\mathrm{s}} / \mu$ values were not recovered to the initial ones. After successive experiments described above, annealed Ti/Al layers were removed by diluted HF. Figures 3(a) and 3(b) show temperature dependences of $n_{\mathrm{s}}$ and $\mu$, respectively, for $\mathrm{Ti} / \mathrm{Al}$

TABLE I. Sheet electron density $\left(n_{\mathrm{s}}\right)$ and mobility $(\mu)$ with varying Ti/Al thickness. $n_{\mathrm{s} 1}$ and $\mu_{1}$ are the initial values and $n_{\mathrm{s} 2}$ and $\mu_{2}$ are after VA ones measured at room temperature. Vacuum annealing were performed at $1020 \mathrm{~K}$ except for Ti/ $\mathrm{Al}=0 / 100 \mathrm{~nm}$ (annealed at $820 \mathrm{~K}$, below the melting point of $\mathrm{Al}$ ).

\begin{tabular}{|c|c|c|c|c|c|c|}
\hline $\mathrm{Ti} / \mathrm{Al}(\mathrm{nm} / \mathrm{nm})$ & $n_{s 1}$ initial $\left(10^{13} \mathrm{~cm}^{-2}\right)$ & $n_{s 2}$ after VA $\left(10^{13} \mathrm{~cm}^{-2}\right)$ & $n_{s 2} / n_{s 1}$ & $\mu_{1}$ initial $\left(\mathrm{cm}^{2} / \mathrm{V} \mathrm{s}\right)$ & $\mu_{2}$ after VA $\left(\mathrm{cm}^{2} / \mathrm{Vs}\right)$ & $\mu_{2} / \mu_{1}$ \\
\hline $15 / 0$ & 0.9 & 0.8 & 0.89 & 1460 & 1250 & 0.86 \\
\hline $100 / 0$ & 0.9 & 1.6 & 1.71 & 1490 & 1360 & 0.91 \\
\hline $15 / 15$ & 1.0 & 1.4 & 1.35 & 1370 & 1730 & 1.26 \\
\hline $50 / 15$ & 0.9 & 5.3 & 6.13 & 1470 & 1710 & 1.16 \\
\hline $15 / 50$ & 1.2 & 12.9 & 11.00 & 1430 & 1970 & 1.38 \\
\hline $100 / 50$ & 1.1 & 14.1 & 13.30 & 1050 & 2150 & 2.05 \\
\hline $0 / 100^{(a)}$ & 7.8 & 4.6 & 0.59 & 2080 & 1900 & 0.91 \\
\hline $15 / 100$ & 1.2 & 19.0 & 15.50 & 1380 & 2090 & 1.51 \\
\hline 100/100 & 1.1 & 11.4 & 11.60 & 1330 & 2190 & 1.65 \\
\hline
\end{tabular}

${ }^{\mathrm{a}}$ Vacuum annealed at $820 \mathrm{~K}$. 


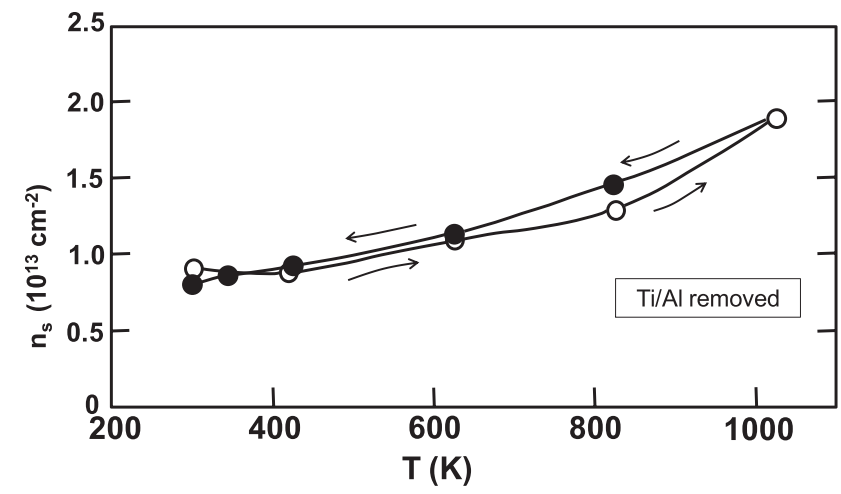

(a)

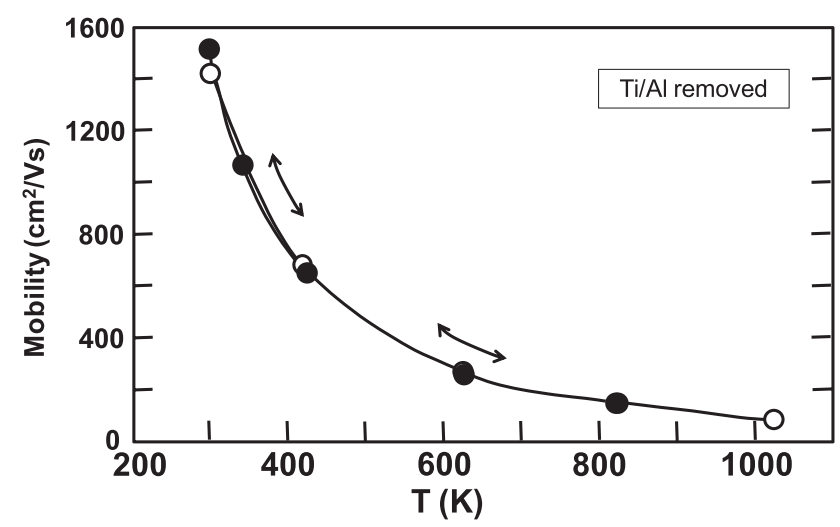

(b)

FIG. 3. Temperature dependence of sheet electron density (a) and mobility (b) for Ti/Al removed sample. Open and closed circles correspond to increasing and decreasing temperatures, respectively. The arrows show the temperature increase/decrease directions.

removed sample. As is clearly seen, no increase in $n_{\mathrm{s}} / \mu$ was observed, and the values were almost recovered to the initial ones (before annealing). The result implies that the increase in $n_{\mathrm{s}} / \mu$ is brought from vacuum annealed Ti/Al layer, not from $\mathrm{AlGaN} / \mathrm{GaN}$ heterostructures.

In order to investigate the origin of increase in $n_{\mathrm{s}} / \mu$, several possibilities are considered. One of them is that the measured $n_{\mathrm{s}} / \mu$ values may correspond to those of the annealed $\mathrm{Ti} / \mathrm{Al}$ metallic layer, and not of electrons at $\mathrm{AlGaN} /$ $\mathrm{GaN}$ interface. However, such a concern is excluded because $\mu$ never exceeds $2000 \mathrm{~cm}^{2} / \mathrm{Vs}$ if electrons flow in the metallic layer. For elaborate measurement, Ti/Al $(15 / 50 \mathrm{~nm})$ was deposited on the whole surface of the epitaxial layer and $n_{\mathrm{S}} / \mu$ were measured. The results were $1.2 \times 10^{18} \mathrm{~cm}^{-2}$ and 3.4 $\mathrm{cm}^{2} / \mathrm{Vs}$ for $n_{\mathrm{s}}$ and $\mu$, respectively, which were quite different by four orders in $n_{\mathrm{s}}$, and three orders of magnitude in $\mu$ from those of $\mathrm{Ti} / \mathrm{Al}$ circular patterns. Therefore, it is concluded that the measured $n_{\mathrm{s}} / \mu$ values correspond to electrons flowing at $\mathrm{AlGaN} / \mathrm{GaN}$ interface.

The $n_{\mathrm{s}}$ at $\mathrm{AlGaN} / \mathrm{GaN}$ interface is determined by the following parameters: surface barrier height $\left(\Phi_{\mathrm{B}}\right)$, band discontinuity between $\mathrm{AlGaN}$ and $\mathrm{GaN}\left(\Delta E_{\mathrm{c}}\right)$, thickness of $\mathrm{AlGaN}$ layer $\left(d_{\mathrm{AlGaN}}\right)$, and polarized charge $\left(\sigma_{\mathrm{p}}\right.$, including spontaneous and piezoelectric), where $\Phi_{\mathrm{B}}, \sigma_{\mathrm{p}}$, and $\Delta E_{\mathrm{c}}$ depend on the $\mathrm{Al}$ composition of $\mathrm{AlGaN}$ layer. Among them, the most probable origin for $n_{\mathrm{s}}$ increase seems to be the change of $\sigma_{\mathrm{p}}$. As shown in Fig. 2, Ti/Al starts to react with AlGaN at around $520 \mathrm{~K}$. Since atomic radii of $\mathrm{Al}$ and $\mathrm{Ti}$ are larger than that of $\mathrm{N}$, the reacted $\mathrm{Al}$ and $\mathrm{Ti}$ atoms, which are introduced interstitially or substituting $\mathrm{N}$ atoms, tend to expand the lattice in AlGaN layer, resulting in the increase of tensile strain. Such enhanced strain remains unchanged even after the temperature decreased to $300 \mathrm{~K}$.

The strain induced by vacuum annealing produces polarized charge. The charge is added to the originally existing polarized charge leading to the net increase of $n_{\mathrm{s}}$. The validity of above mentioned model is supported by the experimental results that $n_{\mathrm{s}}$ increase was not observed for totally thin Ti/Al layer and for Ti/Al removed sample. Within the experiments in this study, it was confirmed that over $65 \mathrm{~nm}$ total thickness of Ti/Al was needed for obtaining high $n_{\mathrm{s}} / \mu$, and $\mathrm{Ti}$ or $\mathrm{Al}$ solely did not cause $n_{\mathrm{s}} / \mu$ increase. It is to be noted that only $\mathrm{Al}$ deposited sample showed extremely high $n_{\mathrm{s}} / \mu$ in the initial values, although they were decreased by vacuum annealing (see row 7 in Table I). This result suggests that Al plays a key role for increasing $n_{\mathrm{s}} / \mu$. The tensile strain is increased by the intrusion of $\mathrm{Al}$ into $\mathrm{AlGaN}$ layer, however, it tends to be relaxed by high temperature annealing. Ti acts to suppress the lattice relaxation by reacting with $\mathrm{Al}$.

The net incremental induced $\sigma_{\mathrm{p}}$ responsible for $n_{\mathrm{s}}$ increase was calculated by using analytical equation and parameters found in Ref. 12. The estimated values were $1.7 \times 10^{-5}, 1.9 \times 10^{-5}$, and $2.2 \times 10^{-5} \mathrm{C} / \mathrm{cm}^{2}$, for $\mathrm{Ti} / \mathrm{Al}$ thickness of $100 / 100,15 / 50$, and $100 / 50 \mathrm{~nm}$, respectively. The reason of the increase in $\mu$ is not clear at present. The induced high sheet density of electrons may screen the polar optical phonon and other dominant scatterings at room temperature, ${ }^{4,13-15}$ or the induced strain may reduce the effective mass of electrons, ${ }^{11}$ though more experimental evidences are needed to confirm it.

In conclusion, a method to increase $n_{\mathrm{s}}$ and $\mu$ for AlGaN/ $\mathrm{GaN}$ heterostructures is described. It is to anneal Ti/Al deposited layer on $\mathrm{AlGaN} / \mathrm{GaN}$ heterostructures at around $1000 \mathrm{~K}$ in vacuum. One order of magnitude higher in $n_{\mathrm{s}}$ and $65 \%$ higher in $\mu$ were observed as compared with the initial values. A model to explain the origin of increase is proposed, which tensile strain is increased with annealing in vacuum. The method described, herein, will be useful for reducing the ohmic contact resistivity and/or the access resistance between source and gate in AlGaN/GaN HEMTs.

The authors are grateful for the support by a Grantin-Aid of Basic Research (C) from the Ministry of Education, Culture, Sports, Science, and Technology, Japan.

${ }^{1}$ O. Ambacher, J. Smart, J. R. Shealy, N. G. Weimann, K. Chu, M. Murphy, W. J. Schaff, L. F. Eastman, R. Dimitrov, L. Wittmer, M. Stutzmann, W. Rieger, and J. Hilsenbeck, J. Appl. Phys. 85, 3222 (1999).

${ }^{2}$ J. P. Ibbetson, P. T. Fini, K. D. Ness, S. P. DenBaars, J. S. Speck, and U. K. Mishra, Appl. Phys. Lett. 77, 250 (2000).

${ }^{3}$ I. P. Smorchkova, C. R. Elass, J. P. Ibbetson, R. Vetury, B. Heying, P. Fini, E. Haus, S. P. Denbaars, J. S. Speck, and U. K. Mishra, J. Appl. Phys. 86, 4520 (1999).

${ }^{4}$ R. Oberhuber, G. Zandler, and P. Vogl, Appl. Phys. Lett. 73, 818 (1998).

${ }^{5}$ M. J. Manfra, L. N. Pfeiffer, K. W. West, H. L. Stormer, K. W. Baldwin, J. W. P. Hsu, and D. V. Lang, Appl. Phys. Lett. 77, 2888 (2000).

${ }^{6}$ C. P. Jiang, S. L. Guo, Z. M. Huang, J. Yu, Y. S. Gui, G. Z. Zheng, J. H. Chu, Z. W. Zheng, B. Shen, and Y. D. Zheng, Appl. Phys. Lett. 79, 374 (2001).

${ }^{7}$ C. M. Jeon, and J. L. Lee, Appl. Phys. Lett. 86, 172101 (2005). 
${ }^{8}$ N. A. Mahadik, S. B. Qadri, and M. V. Rao, Appl. Phys. Lett. 93, 222106 (2008).

${ }^{9}$ F. G. Flores, C. Rivera, and E. Munoz, Appl. Phys. Lett. 95, 203504 (2009).

${ }^{10}$ K. S. Im, J. B. Ha, K. W. Kim, J. S. Lee, D. S. Kim, S. H. Hahm, and J. H. Lee, IEEE Electron Device Lett. 31, 192 (2010).

${ }^{11}$ M. Azize, and T. Palacios, J. Appl. Phys. 108, 023707 (2010).
${ }^{12}$ H. Tokuda, J. Yamazaki, and M. Kuzuhara, J. Appl. Phys. 108, 104509 (2010).

${ }^{13}$ L. Hsu and W. Walukiewicz, Phys. Rev. B 56, 1520 (1997).

${ }^{14}$ R. Gaska, J. W. Yang, A. Osinsky, Q. Chen, M. A. Khan, A. O. Orlov, G. L. Snider, and M. S. Shur, Appl. Phys. Lett. 72, 707 (1998).

${ }^{15}$ R. Dimitov, M. Murphy, J. Smart, W. Schaff, J. R. Shealy, L. F. Eastman, O. Ambacher, and M. Stutzmann, J. Appl. Phys. 87, 3375 (2000). 